\title{
BITCOİN İLE TÜRKIYYE VE G7 ÜLKE BORSALARI ARASINDAKİ UZUN VE KISA DÖNEMLİ İLIŞKILLERIN İNCELENMESİ
}

${ }^{*} \operatorname{Ersin} \mathrm{KANAT}$
**Emrah $\ddot{O} G E T$

\section{Özet}

$\mathrm{Bu}$ çalışmada, isminden son y1llarda sıkça bahsettiren ve kripto paralardan biri olan Bitcoin fiyatı ile Türkiye ve G7 ülkelerine ait borsa endeksleri arasındaki nedensellik ilişkisi incelenmektedir. Bitcoin fiyatlarındaki dalgalanmanın 2013 yılından itibaren başlaması nedeni ile çalışmada 01.01.2013-26.01.2018 arasındaki günlük veriler kullanılmıştır. Çalışmada öncelikle birim kök testleri ve eşbütünleşme analizi gerçekleştirilmiştir. Değişkenler arasındaki ilişkinin uzun dönemde dengede olup olmadığını analiz edebilmek için vektör hata düzeltme modeli (VECM) kullanılmış, kısa dönemli ilişkiler ise Granger Nedensellik/WALD testi yardımıyla incelenmiştir. Yapılan analizler sonucunda, Bitcoin ile diğer ülke borsaları arasında herhangi bir uzun dönemli denge ilişkisinden söz edilemeyeceği bulunurken, kısa dönemde İngiltere borsasının (FTSE) Bitcoin'in nedeni olduğu sonucuna ulaşılmıştır. Ayrıca, Bitcoin'in de S\&P 500 ve Kanada Borsasının (STSX) nedeni olduğu görülmüştür. Sonuç olarak, Bitcoin fiyatının dalgalanması hakkında kısa vadede bu üç borsa endeksinin de fikir verebileceği ortaya çıkmaktadır. Yatırımcılar hem araştırmaya konu olan bu borsalar arasında hem de Bitcoin'e yatırım yaparak risklerini çeşitlendirme yoluna gidebilir.

\section{Anahtar kelimeler: Bitcoin, Eşbütünleşme, VECM}

Jel Kodları: G11, G15, F02

\begin{abstract}
This study aims to investigate the causal relationship between the price of Bitcoin, a cryptocurrency which has become popular over recent years, and the share indices of Turkey and G7 countries. Due to the fact that the fluctuation in the price of Bitcoin started in 2013, this study is based on daily data between the dates of 01.01.2013 and 26.01.2018. Unit root tests and cointegration analyses were carried out, and vector error correction model (VECM) was employed to find out whether relations among variables were stable in the long term, while short term relations were analyzed through Granger Causality/WALD test. The analyses carried out revealed that there was no long term stability between Bitcoin and the share indices of other countries, whereas Financial Times Stock Exchange (FTSE) influenced Bitcoin in shortterm. In addition, it was found that S\&P 500 and Canadian Stock Exchange (STSX) were influenced by Bitcoin in shortterm. Based on these findings, it can be concluded that each of the three aforementioned indices may provide an insight into the fluctuation of Bitcoin prices. Investors may resort to diversify their risks by investing both in these stock markets and in Bitcoin.
\end{abstract}

Keywords: Bitcoin, Co-integration, VECM

JEL Codes: G11, G15, F02

*Dr.Öğr.Üyesi Ersin KANAT, Bülent Ecevit Üniversitesi, Uygulamalı Bilimler Yüksekokulu (ersinkanat@beun.edu.tr)
** Öğr. Gör. Emrah ÖGET, Bülent Ecevit Üniversitesi, Devrek Meslek Yüksekokulu (emrahoget@beun.edu.tr) 


\section{Giriș}

Bitcoin ilk kez 2009 yılında anonim bir şekilde ortaya çıkmıştır. İlk çıkış noktasının ve yaygınlaşmasının ana nedeni olarak genellikle otoriteye karşı yapılmış bir uygulama olduğu savunulur. Özellikle bankaların her işlemde aldığı komisyonların ve çeşitli devlet politikalarının Bitcoin'in yaygınlaşmasında önemli rol oynadığı düşünülmektedir. Bitcoin'in en büyük özelliklerinden biri diğer para birimleri gibi tek bir ülkeye ait olmaması ve tek bir elden üretilmemesidir. Bir diğer önemli özelliği ise bu sanal paranın üretiminin maksimum 21 milyonla sınırlandırılacak şekilde olmasıdır. Bu durum para biriminin yaygınlaşması durumunda, arzın bir yerde sabit kalacağı sebebi ile sürekli değerlenmesine neden olabilir. Nitekim 2009 yılından günümüze kadar gelişimine bakıldığında hızlı bir şekilde yayılma olduğu gözlemlenebilmektedir. Üstelik bu yayılma çeşitli risklere rağmen devam etmektedir. Bu risklerden bazıları; her ülkenin Bitcoin'i resmi olarak kabul etmiyor olması, yasal düzenlemelerde hala eksikliklerin yer alması ve bazılarına göre Bitcoin'deki fiyat artışının bir balon olarak görülmesi gibi konulardır.

Tüm olumlu ve olumsuz yönlerine rağmen bu sanal para çeşidi, günümüzde oldukça önem arz edecek bir yaygın kullanıma erişmiştir. Bugün internet aracılığı ile Bitcoin kullanılarak alınabilecek sınırsız ürün ve hizmet bulunmaktadır. $\mathrm{Bu}$ para birimi her ne kadar çeşitli ülkelerin para birimleriyle kıyaslansa da, genel olarak Amerikan Dolar'1 ile fiyatları takip edilmektedir ve neredeyse Dolar ile internet ortamında bir rekabete girişmektedir. Bu nedenden dolayı, çalışmada Amerikan Doları cinsinden verilerin kullanılması tercih edilmiştir. Yapılmış olan bu araştırmada, Bitcoin ile ülke borsaları arasındaki uzun ve kısa vadeli ilişkiler irdelenmektedir. İlişkilerin incelendiği borsalar, Türkiye ve G7 ülkelerine ait borsalardır. Elde edilen veriler birim kök testi, Eşbütünleşme analizi ve nedensellik testi’ne tabi tutularak, konu hakkında yorum yapılabilmesine zemin hazırlanmıştır.

Kısacası, günümüzde popülaritesi gün geçtikçe artan ve çeşitli tartışmaların ortaya atılmasına sebep olan Bitcoin ile ilgili olarak bu tür bir çalışmanın yararlı olabileceği düşüncesi ortaya çıkmaktadır. Bu amaç doğrultusunda, beş ana bölümden oluşan bir çalışma gerçekleştirilmiştir. Çalışmanın birinci bölümü, genel olarak Bitcoin ve araştırma hakkında temel bilgilerin verilmesini içermektedir. İkinci bölümde ise son zamanlarda yapılmış olan konuyla ilgisi olabilecek bazı önemli çalışmalardan bahsedilmiştir. Üçüncü bölümde çalışmada kullanılan veriler ve araştırmanın yöntemi hakkında bilgilere yer verilmiştir. Dördüncü bölüm, analiz ve sonuçlarının gösterildiği ve yorumlandığı bölümdür. Son bölümde ise araştırmadan elde edilen bulgular 1şı̆̆ında bazı yorum ve tavsiyelerde bulunulmuştur.

\section{Literatür Taraması}

Her ne kadar ilk Bitcoin üretimine 2009 yılında başlanmış olsa da, konuyla ilgili olarak yapılan ilk çalışma 2008 yılında Satoshi Nakamoto ismiyle anılan ve kimliği net olarak bilinmeyen kişi veya kişilerce yapılmıştır. Nakamoto internet ortamında yayınladığı makalede Bitcoin'i duyurmuş ve daha önceki dijital paralardan farklı olarak, çalışma prensibi iki taraflı (Peer to Peer) elektronik bir ödeme sisteminden bahsetmiştir. Bu çalışmada sistemin işleyişi ve paranın transfer şekli gibi konulara değinilmiştir (Nakamoto, 2008).

Dijital paranın bir çeşidi olan Bitcoin'le ilgili bu çalışmadan sonra literatürde sınırsız sayıda çalışma ve görüş yer almıştır. Bu çalışmalar dünyada olduğu gibi Türkiye'de de oldukça ilgi çekmektedir ve para biriminin geleceği hakkında insanlarda büyük bir merak uyandırmaktadır. Konuyla ilgili olarak son zamanlarda yapılmış bazı önemli çalışmalar kronolojik olarak aşağıda bahsedilmeye çalışılmıştır.

Konuyla alakalı olabilecek ve güncel tartışmalara ışık tutabilecek önemli bir çalışma Glaser vd. (2014) tarafından yapılmıştır. "Bitcoin - Asset or Currency? Revealing Users' Hidden Intentions" başlıklı çalışmada araştırmacılar Bitcoin'in gerçekten bir para birimi olarak mı, yoksa gelir elde etmek için bir varlık olarak mı kullanıldığını araştırmışlardır. Çalışmalarında; Bitcoin kullanan çok sayıda insanın, Bitcoin'i alternatif bir parasal sistem yerine, alternatif bir yatırım aracı olarak gördükleri bulgusuna ulaşmışlardır.

Sönmez (2014) ise "Sanal Para Bitcoin” başlıklı çalışmasında Bitcoin’in ne olduğunu detaylı bir şekilde ortaya koymuştur. Çalışmada; Bitcoin'in ilk meydana gelişi, gelişimi, güçlü yanları, dezavantajları ve özellikleri gibi birçok konuya değinilmiştir. Genel olarak bu kripto para biriminin ne olduğunun anlaşılabilmesi açısından incelenebilecek bir kaynak olduğu düşünülmektedir. Sönmez'in çalışmasında geçen ve dikkat çeken bir tavsiyesi; bu para biriminin kalıcı bir para birimi olup olamayacağının araştırılması ve gelecek dönemlerde bu amaç ile Bitcoin'in takip edilmesidir. 
Gupta vd.(2015), Bitcoin'in elektronik ticaret içerisindeki yerini ve önemi gösteren "Dependability of Bitcoin in E-Commerce" isimli çalışmayı yapmışlardır. Sonuç olarak birçok kişiye göre geleceğin para birimi olarak nitelendirilen bir unsurun, ticaret içerisindeki yeri ve engelleri gibi konularının araştırılması göreceli olarak önem arz etmektedir. Kısaca çalışma, Bitcoin'in alışverişlerde kullanılması konusundaki risklerini ve elektronik ticarette Bitcoin'in avantajlı duruma getirilmesi ile ilgili önerileri içermektedir.

Atik vd.(2015), “Kripto Para: Bitcoin ve Döviz Kurları Üzerine Etkileri” isimli çalışmada döviz kurları ile Bitcoin arasındaki ilişkiyi Granger Nedensellik Testi’ni kullanarak incelemişlerdir. Yazarlar analizlerinde kullanmak için çapraz döviz kuru olarak; Euro, İngiliz Sterlini, Japon Yeni, Kanada Doları, Avustralya Doları ve İsviçre Frankı'nı seçmişlerdir. Analizleri sonucunda; Japon Yeni’nden Bitcoin’e doğru bir nedensellik ilişkisi gözlemlemişlerdir.

Gültekin ve Bulut (2016), "Bitcoin Ekonomisi: Bitcoin Eko-Sisteminden Doğan Yeni Sektörler ve Analizi" başlıklı bir araştırma yapmışlardır. Araştırmacıların esas amacı, Bircoin'in doğurduğu yeni sektörlerin incelenmesi ve bu alt sektörlerin geleceğinin analiz edilmesidir. Çalışmalarında üstünde durdukları konular; altyapı yatırımları, finansal hizmetler, para piyasaları, Bitcoin madenciliği, e-cüzdan ve ödeme işlemcileridir.

Koçoğlu vd.(2016), Bitcoin'in güvenilir bir yatırım aracı olarak kullanılabilirliğini ölçmek amacıyla "Bitcoin Piyasalarının Etkinliği, Likiditesi ve Oynaklığı” isimli bir çalışma yapmışlardır. Çalışmalarında Bitcoin piyasasının işleyişi ve fiyatların oluşumu ile ilgili bilgilere de yer vermişlerdir. Ağırlıklı olarak Bitcoin piyasasının etkinliği, likiditesi ve oynaklığı üzerinde yapılmış olan analizleri içeren çalışma sonucunda, oynaklığın aşırı yüksek olduğu ve dolayısıyla çok riskli olmasının yanında spekülatif amaçla kullanılabilirliğine dikkat çekmişlerdir.

Dirican ve Canoz (2017), ARDL sınır testi yöntemini kullanarak Bitcoin ve bazı borsa endeksleri arasındaki ilişkiyi incelemişlerdir. "Bitcoin Fiyatları ile Dünyadaki Başlıca Borsa Endeksleri Arasındaki Eşbütünleşme İlişkisi: ARDL Modeli Yaklaşımı ile Analiz” başııklı çalışmada, yazarların kullandıkları endeksler Bist100, ChinaA50, Dow30, Ftse100, Nasdaq100, Nikkei225 ve S\&P500 olarak seçilmiştir. Çalışmaları sonucunda, ABD ve Çin Borsa endeksleri ile Bitcoin arasında uzun dönemli bir ilişkinin olduğunu gözlemlemişlerdir.

Gandal vd. (2018), "Price Manipulation in the Bitcoin Ecosystem” başlıklı çalışmada Bitcoin fiyatlarındaki manipülasyonlara dikkat çekmek istemişlerdir. Yapmış oldukları çalışmada, şüpheli ticaret aktivitelerindeki değişim ile Bitcoin fiyatlarının artışı arasında büyük bir ilişki olduğunu savunmuşlardır. Bu nedenle küresel bir ödeme sistemi haline dönüşmeye başlayan Bitcoin sisteminin belirli yasalar ve politikalar ile daha güvenilir bir ortama dönüştürülmesi tavsiye edilmiştir.

\section{VERILER VE YÖNTEM}

\subsection{Veri Seti}

Çalışmada Bitcoin ile Türkiye ve G7 ülke borsaları arasındaki uzun ve kısa dönemli ilişkileri incelemek amaçlanmış ve 01.01.2013-26.01.2018 dönemine ait 1116 günlük verilerin doğal logaritmaları kullanılmıştır. Başlangıç tarihinin 2013 yılı olarak seçilmesinin nedeni Bitcoin'deki dalgalanmaların o tarihte başlayarak günümüze kadar dalgalı bir şekilde artış göstermesiyken, günlük veriler ile çalışılmasının nedeni ise zaman periyodunun kısa olmasıdır. Eryiğit ve Öget (2015;13)'e göre zaman periyodunun kısa olduğu durumlarda yıllık veriler yerine günlük veriler ile çalışılması analizin güven seviyesini yükseltmektedir. Ayrıca, G7 ülkelerinin 2014 yılından itibaren, Rusya'nın G8 üyeliğinin askıya alınmasından sonra ortaya çıktığı bilinmektedir. Ancak Bitcoin fiyatlarındaki dalgalanmalardan dolayı zaman serisinin 2013 yılından başlaması nedeniyle; 2014 yılından itibaren kabul gören G7 ülkelerinin borsa değerleri 2013 y1lından itibaren incelenmeye başlanmıştır. Bitcoin'e ilişkin veriler; Blockchain, Borsa İstanbul 100 endeksine ilişkin veriler; Borsa Ístanbul ve G7 ülke borsalarına ilişkin veriler ise Yahoo Finance web adreslerinden alınmıştır. Çalışmada kullanılan değişkenler; LNBİST100 (Türkiye), LNBTC (Bitcoin), LNCAC40 (Fransa), LNDAX (Almanya), LNFTSE100 (İngiltere), LNFMIB (İtalya), LNNIK225 (Japonya), LNSP500 (Amerika) ve LNSTSX (Kanada) olarak gösterilmiştir. Analizlerin tamamı E-Views 9 ekonometrik analiz programı kullanılarak gerçekleştirilmiştir.

Analize başlamadan önce logaritmik serilere ait tanımlayıcı istatistikler ve korelasyon katsayıları hesaplanarak Tablo 1 ve Tablo 2'de listelenmiştir. 
Tablo 1: Bitcoin Ve Türkiye İle G7 Ülkelerine İlişkin Borsalar İçin Tanımlayıcı İstatistikler

\begin{tabular}{|c|c|c|c|c|c|c|}
\hline VERİLER & Ortalama & Std. Sapma & Maksimum & Minimum & Çarpıklık & Basıklık \\
\hline LNBTC & 6.211736 & 1.285542 & 9.867331 & 9.867331 & 0.283772 & 3.989159 \\
\hline LNBİST & 11.31375 & 0.133178 & 11.70108 & 11.70108 & 0.754678 & 3.376712 \\
\hline LNCAC & 8.421544 & 0.105275 & 8.620109 & 8.620109 & -0.071982 & 2.245628 \\
\hline LNDAX & 9.236223 & 0.148450 & 9.514850 & 9.514850 & -0.124651 & 2.226710 \\
\hline LNFMIB & 9.883826 & 0.121613 & 10.08708 & 10.08708 & -0.269929 & 1.906339 \\
\hline LNFTSE & 8.813831 & 0.065646 & 8.959137 & 8.959137 & 0.064564 & 2.382502 \\
\hline LNNIK & 9.740466 & 0.167269 & 10.09097 & 10.09097 & -0.444045 & 2.919640 \\
\hline LNSP500 & 7.616448 & 0.142476 & 7.963067 & 7.963067 & -0.139453 & 2.695259 \\
\hline LNSTSX & 9.565220 & 0.079448 & 9.705825 & 9.705825 & -0.413772 & 2.049632 \\
\hline
\end{tabular}

Tablo 2: Bitcoin Ve Türkiye İle G7 Ülkelerine İlişkin Borsalar İçin Korelasyon Katsayıları

\begin{tabular}{|c|c|c|c|c|c|c|c|c|c|}
\hline & LNBTC & LNBİST & LNCAC & LNDAX & LNFMIB & LNFTSE & LNNIK & LNSP500 & LNSTSX \\
\hline LNBTC & 1 & 0.5915 & 0.7492 & 0.7933 & 0.4563 & 0.6963 & 0.7296 & 0.8735 & 0.7254 \\
\hline LNBİST & 0.5915 & 1 & 0.6274 & 0.6403 & 0.3736 & 0.6888 & 0.5692 & 0.6680 & 0.5533 \\
\hline LNCAC & 0.7492 & 0.6274 & 1 & 0.9787 & 0.7825 & 0.7265 & 0.9196 & 0.9049 & 0.7977 \\
\hline LNDAX & 0.7933 & 0.6403 & 0.9787 & 1 & 0.6867 & 0.7364 & 0.9311 & 0.9525 & 0.8268 \\
\hline LNFMIB & 0.4563 & 0.3736 & 0.7825 & 0.6867 & 1 & 0.4501 & 0.6744 & 0.5534 & 0.5968 \\
\hline LNFTSE & 0.6963 & 0.6888 & 0.7265 & 0.7364 & 0.4501 & 1 & 0.5778 & 0.7129 & 0.8184 \\
\hline LNNIK & 0.7296 & 0.5692 & 0.9196 & 0.9311 & 0.6744 & 0.5778 & 1 & 0.9047 & 0.6981 \\
\hline LNSP500 & 0.8735 & 0.6680 & 0.9049 & 0.9525 & 0.5534 & 0.7129 & 0.9047 & 1 & 0.8430 \\
\hline LNSTSX & 0.7254 & 0.5533 & 0.7977 & 0.8268 & 0.5968 & 0.8184 & 0.6981 & 0.8430 & 1 \\
\hline
\end{tabular}

\subsection{Yöntem}

Çalışmada verilere ilişkin tanımlayıcı istatistiklere yer verildikten sonra ilk olarak Augmented Dickey Fuller ve Phillips Perron Birim Kök testleri yapılmıştır. Seviye değerlerinde durağan çıkmayan serilerimizin tamamı her iki test istatistiği için de birinci farklarında durağan çıkmıştır. Birinci farkları ile çalışan logaritmik verilerin grafikleri Şekil 1'de gösterilmiştir. Eşbütünleşme analizi için serilerin birim kök araştırmasından sonra optimum gecikme uzunluğunun belirlenmesi için literatürde sıklıkla kullanılan Akaike (AIC), Schwarz (SC) ve Hannan-Quinn (HQ) bilgi kriterleri kullanılmıştır. Gecikme uzunluğu belirlendikten sonra Engle-Granger (1987) tarafindan ortaya konulan ve daha sonra Johansen (1988, 1991), Johansen ve Juselius (1990) tarafından geliştirilen VAR modeline dayalı Johansen yöntemiyle eşbütünleşme analizi gerçekleştirilmiştir. Eşbütünleşme testinde deterministik bileşenler seçilirken Johansen ve Jeselius (1992) tarafından önerilen Puntula prensibi kullanılmıştır. Eşbütünleşme analizi sonuçlarına göre serilerin uzun dönemde birlikte hareket ettiğinin anlaşılması üzerine kısa dönem dinamiklerinin araştırılması için Vektör Hata Düzeltme Modeli (VECM) tahmin edilmiş ve son olarak seriler arasındaki nedensellik ilişkisi WALD testi yardımıyla incelenmiştir.

\subsubsection{Birim Kök Testleri}

Zaman serisi verileri ile çalışırken serilerin aynı seviyede durağan olması önemlidir. Aksi taktirde değişkenler arasında gerçekten bir ilişki olmamasına rağmen durağan olmayan değişkenlerin trendinden kaynaklı bir ilişki görünebilir ve bu da sahte regresyon sorununa yol açar (Chen ve Chen, 2009; 384). Ayrıca serilerin aynı seviyede durağan olmaları eşbütünleşme analizi için ön koşuldur (Altıntaş ve Mercan, 2015; 364). Bitcoin ile Türkiye ve G7 ülke borsaları arasındaki nedensellik ilişkileri araştırılmadan önce durağanlık sınaması için birim kök analizi yapılmıştır. Bunun için Dickey ve Fuller (1979) tarafından geliştirilen Augmented Dickey Fuller (ADF) ve Phillips ve Perron (1988) tarafından geliştirilen Phillips-Perron (PP) testlerinden yararlanılmıştır. ADF Birim kök testi ile ilgili formüller şu şekilde ifade edilebilir (Eryiğit ve Öget, 2015; 17);

$$
\Delta Y_{t}=p Y_{t-1}+\sum_{i=1}^{p} \delta Y_{t-i}+u_{t} \quad \text { sabitsiz ve trendsiz model için }
$$




$$
\begin{array}{ll}
\Delta Y_{t}=a+p Y_{t-1}+\sum_{i=1}^{p} \delta Y_{t-i}+u_{t} & \text { sabitli model için, } \\
\Delta Y_{t}=a+\beta_{t}+p Y_{t-1}+\sum_{i=1}^{p} \delta Y_{t-i}+u_{t} & \text { sabitli ve trendli model için. }
\end{array}
$$

Birim kök için oluşturulan temel hipotez $H_{0}: p=0$ (Y değişkeni birim kök içerir). Diğer yandan alternatif hipotez Y değişkenin birim kök içermediğini, yani durağan olduğunu gösterir $\left(H_{0}: p<0\right)$. Bir değişken durağan ise yani birim kök içermiyorsa düzeye ya da I(0)'da entegre olduğu söylenir. Herhangi bir seride istikrarsılık mevcutsa orijinal serilerin farkı alındıktan sonra test tekrar yapılır. Serilerin düzeyde durağan olmaması ancak birinci farklarında durağan olması durumunda birinci seviyede ya da I(1)'de entegre olduğu söylenir.

Literatürde durağanlık analizinde yaygın olarak Dickey ve Fuller (1979) tarafından geliştirilen testlerin yanısıra Phillips ve Perron (1988) tarafından geliştirilen PP testi de kullanılmaktadır. Dickey-Fuller birim kök testi hata terimlerinin istatistiki olarak bağımsız olduklarını ve sabit varyansa sahip olduklarını varsayar.(Enders, 2004; 190). Bu varsayım modelin otokorelasyon durumunu içermemesinden dolayı eleştirilmektedir. ADF testinde ise modele gecikmeli değerler eklenerek Dickey-Fuller (1979) testi Genişletilmiş Dickey-Fuller (1981) olarak yeniden sunulmuş ve DF testini otokorelasyon sorununa karşı düzeltmiştir (Özcan, 2015; 589). PP testi ise parametrik olmayan yöntemlerle DF testinin geliştirilmiş halidir (Çağlayan ve Saçaklı, 2006; 121). PP birim kök testi hata teriminin zayıf derecede bağımlı olmasına ve heterojen olarak dağılmasına izin vererek otokorelasyon sorununu ortadan kaldırmaktadır (Enders, 2004; 229). PP testi hatalarda meydana gelen serisel korelasyon ve değişen varyans sorunu ile baş etme konusunda ADF testinden ayrılmaktadır (Uğurlu, 2009; 12). Test için denklem aşağıdaki şekilde ifade edilebilir (Çağlayan ve Saçaklı, 2006;124);

$$
\Delta Y_{t}=a Y_{t-1}+x_{1}^{\prime} \delta+\varepsilon_{t}
$$

burada a $=$ p-1 iken $x_{1}^{\prime}$ ise sabit veya sabit ve trend'i ifade eden deterministik bileşendir. PP testinde parametrik olmayan düzeltmeler yapılmaktadır. Bu nedenle otokorelasyon, test istatistiğinin asimtotik dağılımını etkilememektedir. $\mathrm{Bu}$ düzeltmeler sıfır frekansta $\varepsilon_{t}$ 'nin spektrum tahminine dayanır ve tutarlı tahminlere olanak verir. Test istatistiği için denklem aşağıdaki şekilde ifade edilir (Çağlayan ve Saçaklı, 2006;124);

$$
\hat{\mathrm{t}}_{\mathrm{a}}=t_{a}\left(\left(\frac{\gamma_{0}}{f_{0}}\right)^{-\frac{1}{2}}-\frac{T\left(f_{0}-\gamma_{0}\right)\left(s_{e}(\hat{a})\right)}{a f_{0}^{1 / 2} s}\right.
$$

burada $s_{e}(\hat{a})$ katsayı standart hatası, $s$ denklemin standart hatası, T gözlem sayısı, $\gamma_{0}$ hata varyansının tutarlı tahmini ve $f_{0}$ ise sıfır frekansta artık spektrumunun tahmincisidir. PP testinde temel hipotez $\mathrm{H}_{0}: \mathrm{a}=0$ (birim kök vardır), $\mathrm{H}_{1}: \mathrm{a}<0$ (birim kök yoktur) şeklinde kurulur. Test istatistiğinin asimtotik dağılımı ADF testi ile aynıdır ve McKinnon kritik değerleri ile karşılaştırılabilir.

\subsubsection{Johansen Eşbütünleşme Analizi}

Eşbütünleşme yöntemi, Granger (1981) ve Engle ve Granger (1987) tarafından ekonometri literatürüne kazandırılmıştır. Bu yönteme göre iki entegre değişken ortak bir stokastik eğilim paylaşıyorsa, bu değişkenlerin doğrusal kombinasyonları da durağan olur ve buna ortak entegre denir. Bu durumda bu değişkenlerin doğrusal kombinasyonları da eşbütünleşme vektörünü oluşturmaktadır çünkü durağan değişkenlerin doğrusal kombinasyonları da durağandır (Kilian ve Lütkepohl, 2017; 74-75). Eşbütünleşme analizi sayesinde birbirleriyle ilişkili olduğu düşünülen çok sayıda ekonomik değişkenden iki veya daha fazlasının uzun dönemde birlikte hareket edip etmediği ortaya çıkarılabilmektedir (Bayraktutan ve Arslan, 2008; 9). Serilerin durağanlığını sağlamak için farklarının alınması sadece kısa dönemli şokları yok etmemekte aynı zamanda serilerde uzun dönemli ilişkilerin de yok olmasına neden olabilmektedir. Eşbütünleşme teorisi fark alma yoluyla değişkenler arasında kısa ve uzun dönemli bilgilerin kaybolmasını önleyerek tutarlı bir analizin yapılmasına olanak sağlamaktadır (Işık, Acar ve Işık, 2004; 332).

Johansen (1988) eşbütünleşme testinde aynı seviyede durağan olan serilerin denklem sistemi, sistemde yer alan her değişkenin düzey ve gecikmeli değerlerinin yer aldığı Vector Auto-Regressive (VAR) analizine dayanmaktadır. Denklem sistemi aşağıdaki gibidir (Tarı ve Yıldırım, 2009; 100);

$$
\Delta \mathrm{x}_{\mathrm{i}}=\Gamma \Delta x_{t-1}+\cdots+\Gamma_{k-1} \Delta X_{t-k}+\Pi \Delta x_{t-k}+\varepsilon_{t}
$$




$$
\Gamma_{\mathrm{i}}=-I+\Pi_{1}+\cdots+\Pi_{i}, \quad i=1, \ldots, k
$$

burada $\Pi$ katsayılar matrisidir ve bu matrisin rankı sistemde var olan eşbütünleşme ilişkisi sayısını vermektedir. Eğer bu matrisin rankı sıfira eşit ise bu durumda $X$ vektörünü oluşturan değişkenler arasında eşbütünleşme ilişkisinin var olmadığı sonucu ortaya çıkar. Rankın 1'e eşit olması değişkenler arasında bir adet eşbütünleşme ilişkisinin varlığını gösterirken 1'den büyük olması değişkenler arasında birden çok eşbütünleşme ilişkisinin varlığını gösterir. Johansen ve Jeselius (1990) eşbütünleşme testinde değişkenler arasında eşbütünleşik bir ilişkinin varlığını sınamak için iki test istatistiği geliştirmiştir (iz istatistiği(trace) ve maksimum özdeğer istatistiği (max eigenvalue)). Bunlar (Pınarönü, 2007;33);

$$
\begin{aligned}
& \lambda_{\text {trace }}=-n \sum_{i=r+1}^{p} \ln \left(1-\hat{\lambda}_{i}\right) \\
& \text { ve } \\
& \lambda_{\max }=-n \ln \left(1-\hat{\lambda}_{r+1}\right)
\end{aligned}
$$
özetlenmiştir.

istatistik değerleridir. $\lambda_{\mathrm{i}}, \Pi$ matrisinin özdeğerleri, $\mathrm{n}$ ise örnek çapıdır. Kurulan hipotez yapıları aşağıdaki tabloda

Tablo 3: Johansen Testinin Hipotez Yapıları

\begin{tabular}{|c|c|}
\hline $\mathrm{H}_{0}$ hipotezi & $\mathrm{H}_{1}$ hipotezi \\
\hline$\lambda_{\text {trace }}$ & $\lambda_{\text {trace }}$ \\
$\mathrm{r}=0$ & $\mathrm{r} \geq 1$ \\
$\mathrm{r} \leq 1$ & $\mathrm{r} \geq 2$ \\
$\mathrm{r} \leq 2$ & $\mathrm{r} \geq 3$ \\
\hline$\lambda_{\max }$ & $\lambda_{\max }$ \\
$\mathrm{r}=0$ & $\mathrm{r}=1$ \\
$\mathrm{r}=1$ & $\mathrm{r}=2$ \\
$\mathrm{r}=2$ & $\mathrm{r}=3$ \\
\hline
\end{tabular}

Bu testlerde kullanılan kritik değerler Monte Carlo yaklaşımına dayanmaktadır. Her iki test istatistiği için null hipotezi $r=0$ eşbütünleşme ilişkisinin olmadığını gösterirken alternatif hipotez $r=1,2,3$ ya da 4 adet eşbütünleşme ilişkisinin varlığını ifade etmektedir. (Enders, 2004; 354). VAR modeli için oluşturulan genel eşitliğin modelimize uyarlanması aşağıdaki gibidir;

$$
\begin{aligned}
& \boldsymbol{L N B T C}_{\boldsymbol{t}}=a_{0}+\sum_{i=1}^{p} a_{1} L_{N B T C} C_{t-i}+\sum_{i=1}^{p} a_{2} L N B \dot{\mathrm{I} S T} T_{t-i}+\sum_{i=1}^{p} a_{3} L N C A C_{t-i}+\sum_{i=1}^{p} a_{4} L N D A X_{t-i}+ \\
& \sum_{i=1}^{p} a_{5} \text { LNFTSE }_{t-i}+\sum_{i=1}^{p} a_{6} \text { LNFMIB }_{t-i}+\sum_{i=1}^{p} a_{7}{\text { LNSP } 500_{t-i}}+\sum_{i=1}^{p} a_{8} \text { LNNIK }_{t-i}+\sum_{i=1}^{p} a_{9} \text { LNSTSX }_{t-i}+\varepsilon_{t}
\end{aligned}
$$

$\mathrm{Bu}$ eşitlikte $\mathrm{p}$ optimum gecikme uzunluğunu gösterirken, $\varepsilon_{t}$ ise hata terimini ifade etmektedir. Denklem kalabalığına yer vermemek adına tek eşitlik yazılarak Bitcoin (LNBTC) bağımlı değişken olarak seçilmiştir. Her değişken bir kez bağımlı değişken olarak yazılarak eşitlik sayısı artırılabilir.

\subsubsection{Granger Nedensellik Testi ve Vektör Hata Düzeltme Modeli}

Zaman serileri ile yapılan ekonometrik çalışmalarda, nedensellik ilişkilerinin bulunabilmesi için Granger'ın 1969 yılında oluşturduğu yöntem oldukça yaygın bir şekilde kullanılmaktadır. Bu yönteme göre; eğer bir X değişkeninin gecikmeli değeri, Y değişkenin değerlerinin tahmin edilmesine yardımcı oluyorsa; X, Y'nin Granger nedenidir diye düşünülmektedir. Nedensellik testinin uygulanabilmesi için kullanılabilecek farklı modeller olmasına karşılık, genellikle Var modeline dayalı yöntem kullanılır. Ancak, Engel ve Granger’a göre eğer seriler eşbütünleşikse, Var modeline dayalı Granger nedensellik testinin geçerliliği söz konusu olamayacaktır. (Demirci, 2017; 53) 
Değişkenler arasında eşbütünleşme ilişkisi varsa, bu değişkenler arasında en azından tek yönlü bir nedensellik bulunması gerekmektedir. Bu nedensellik analizi ise Vektör Hata Düzeltme Modeli (VECM) yardımı ile yapılabilmektedir. Serilerin durağanlaştırılması için uyguladığımız fark işlemi serilerin uzun dönem bilgilerinde kayıplara neden olabilmektedir. VECM sahte ilişkilere olanak vermeden verilerin kısa ve uzun dönem bilgilerinin kullanılmasını yani fark işleminin neden olduğu kayıpların ortadan kaldırılmasını sağlar (Kolçak, Kalabak ve Boran, 2017; 480). Engle ve Granger tarafından ortaya konulan hata düzeltme mekanizmasını araştırma modelimize uyarladığımızda aşağıdaki eşitliği elde ederiz;

$$
\begin{aligned}
& \quad \Delta \text { LNBTC }_{t}=a_{0}+\sum_{i=1}^{p} a_{1} \Delta L N B T C_{t-i}+\sum_{i=1}^{p} a_{2} \Delta L N B \dot{\mathrm{I} S T} T_{t-i}+\sum_{i=1}^{p} a_{3} \Delta L N C A C_{t-i}+\sum_{i=1}^{p} a_{4} \Delta L N D A X_{t-i}+ \\
& \sum_{i=1}^{p} a_{5} \Delta L N F T S E_{t-i}+\sum_{i=1}^{p} a_{6} \Delta L N F M I B_{t-i}+\sum_{i=1}^{p} a_{7} \Delta L N S P 500_{t-i}+\sum_{i=1}^{p} a_{8} \Delta L N N I K_{t-i}+ \\
& \sum_{i=1}^{p} a_{9} \Delta L N S T S X_{t-i}+\delta_{1} E C_{t-1}+\varepsilon_{t}
\end{aligned}
$$

Modelde yer alan $\Delta$, ilgili logaritmik verilerin birinci farklarını, p ise optimal gecikme uzunluklarını göstermektedir. Modelde $E C_{t-1}$ uzun dönemli ilişkiden elde edilen hata terimlerinin bir gecikmeli değerini göstermektedir. $E C_{t-1}$ 'in katsayısı olan $\delta_{1}$ 'in negatif ve istatistiksel olarak anlamlı olması beklenir ve seriler arasında meydana gelebilecek bir dengesizliğin ne kadarının bir dönem sonra giderileceğini gösterir. Denklem kalabalığına yer vermemek adına tek eşitlik yazılmıştır. Modelde yer alan tüm değişkenleri bir kez bağımlı değişken yaparak eşitlik sayısı çoğaltılabilir.

\section{Analiz ve Sonuçlar}

Bitcoin ve G7 ülke borsalarının birlikte hareket edip etmediğini incelemeye tabi tutmadan önce verilerimizin durağan olup olmadığını sınamamız gerekmektedir. Çalışmanın güvenilir olması için öncelikle kullanılacak olan verilerin durağan olması veya birinci seviyede durağan olmaları gerekmektedir. Serilerin durağanlığını belirlemek için literatürde sıklıkla kullanılan Augmented Dickey Fuller ve Phillips Perron Birim Kök testi sınamaları yapılarak aşağıdaki tablolarda listelenmiştir.

Tablo 4: Augmented Dickey Fuller Birim Kök Testi Sonuçları

\begin{tabular}{|l|cc|cc|}
\hline ADF & \multicolumn{2}{|c|}{ Seviye Değerleri I(0) } & \multicolumn{2}{c|}{ Birinci Farklar I(1) } \\
\hline Değişkenler & Trendsiz Model & Trendli & Trendsiz Model & Trendli Model \\
& t-istatistiği & Model t-istatistiği & t-istatistiği & t-istatistiği \\
\hline LNBTC & $-1.463148(1)$ & $-1.947601(1)$ & $-30.23533(0)^{* * *}$ & $-30.22627(0)^{* * *}$ \\
LNBİST & $-0.778173(0)$ & $-1.953086(0)$ & $-34.90930(0)^{* * *}$ & $-34.94556(0)^{* * *}$ \\
LNDAX & $-1.405398(0)$ & $-2.787682(0)$ & $-32.44924(0)^{* * *}$ & $-32.43488(0)^{* * *}$ \\
LNFTSE & $-2.130527(0)$ & $-2.696813(0)$ & $-18.29421(3)^{* * *}$ & $-18.28738(3)^{* * *}$ \\
LNNIK & $-2.124748(0)$ & $-3.100963(0)$ & $-36.00991(0)^{* * *}$ & $-36.00241(0)^{* * *}$ \\
LNFMIB & $-1.984293(0)$ & $-2.184527(0)$ & $-35.02346(0)^{* * *}$ & $-35.00852(0)^{* * *}$ \\
LNSTSX & $-1.565487(0)$ & $-2.132116(0)$ & $-31.11405(0)^{* * *}$ & $-31.10006(0)^{* * *}$ \\
LNSP500 & $-0.748198(0)$ & $-2.599184(0)$ & $-32.85419(0)^{* * *}$ & $-32.83974(0)^{* * *}$ \\
LNCAC & $-1.890563(0)$ & $-3.188453(0)$ & $-32.99845(0)^{* * *}$ & $-32.98365(0)^{* * *}$ \\
\hline
\end{tabular}

Not: Kritik değerler MacKinnon (1996)'dan alınmış olup trendsiz model için -3.436004(\%1), -2.863925(\%5), $2.568091(\% 10)$ ve trendli model için $-3.966299(\% 1),-3.413848(\% 5),-3.129002(\% 10)$ şeklindedir. *: \%10, **: \%5 ve ***: \%1 seviyesinde anlamlılığı ifade etmektedir. Parantez içindeki değerler Schwarz Bilgi Kriteri (SIC) kullanılarak belirlenmiş optimum gecikme uzunlularıdır. 
Tablo 5: Phillips Perron Birim Kök Testi Sonuçları

\begin{tabular}{|l|cc|cc|}
\hline PP & \multicolumn{2}{|c|}{ Seviye Değerleri I(0) } & \multicolumn{2}{c|}{ Birinci Farklar I(1) } \\
\hline Değişkenler & Trendsiz Model & Trendli & Trendsiz Model & Trendli Model \\
& t-istatistiği & Model t-istatistiği & t-istatistiği & t-istatistiği \\
\hline LNBTC & $-1.457548(6)$ & $-1.951197(6)$ & $-30.29051(4)^{* * *}$ & $-30.28118(4)^{* * *}$ \\
LNBİST & $-0.710493(1)$ & $-1.912141(2)$ & $-34.90930(0)^{* * *}$ & $-34.92803(2)^{* * *}$ \\
LNDAX & $-1.385438(6)$ & $-2.817510(3)$ & $-32.44874(7)^{* * *}$ & $-32.43358(7)^{* * *}$ \\
LNFTSE & $-2.143466(4)$ & $-2.763521(3)$ & $-31.80517(7)^{* * *}$ & $-31.79041(7)^{* * *}$ \\
LNNIK & $-2.060392(6)$ & $-2.949190(7)$ & $-36.11942(5)^{* * *}$ & $-36.11360(5)^{* * *}$ \\
LNFMIB & $-1.867920(4)$ & $-2.066557(4)$ & $-35.18882(7)^{* * *}$ & $-35.17341(7)^{* * *}$ \\
LNSTSX & $-1.612734(3)$ & $-2.228835(2)$ & $-31.04160(5)^{* * *}$ & $-31.02683(5)^{* * *}$ \\
LNSP500 & $-0.575000(15)$ & $-2.343455(12)$ & $-33.29769(15)^{* * *}$ & $-33.28051(15)^{* * *}$ \\
LNCAC & $-1.718378(9)$ & $-3.064601(6)$ & $-33.27106(11)^{* * *}$ & $-33.25406(11)^{* * *}$ \\
\hline
\end{tabular}

Not: Kritik değerler MacKinnon (1996)'dan alınmış olup trendsiz model için -3.436004(\%1), -2.863925(\%5), $2.568091(\% 10)$ ve trendli model için $-3.966299(\% 1),-3.413848(\% 5),-3.129002(\% 10)$ şeklindedir. *: \%10, **: \%5 ve ***: \%1 seviyesinde anlamlılı̆̆ ifade etmektedir. Parantez içindeki değerler bant genişliği olup Bartlett Kernel modeli kullanılarak Newey-West göre belirlenmiştir.

Tablo 3 incelendiğinde seviyede durağan olmayan verilerin \%1 anlamlılık seviyesinde birinci farklarında durağan olduğu görülmektedir. Eşbütünleşme analizine başlamadan önce parametrik olmayan yöntemlerle Dickkey Fuller testinin geliştirilmiş hali olan Phillips Perron Birim Kök testi de yapılmış ve sonuçları Tablo 4’te listelenmiştir.

Tablo 4 incelendiğinde Tablo 3'teki sonuçlara paralel olarak seviyede durağan olmayan verilerin birinci farklarında I(1), \%1 anlamlılık seviyesinde durağan olduğu görülmektedir. ADF ve PP birim kök testi sonuçları, Johansen Eşbütünleşme testi için verilerimizin gerekli ön koşulu sağladığını göstermektedir. Bundan sonraki kısımda Johansen Eşbütünleşme testi yapılacak ve değgişkenler arasında uzun dönemli bir ilişkinin olup olmadığg ortaya konulmaya çalışılacaktır.

\section{Şekil 1: Çalıșmada Kullanılan Logaritmik Verilerin Birinci Fark Grafikleri}

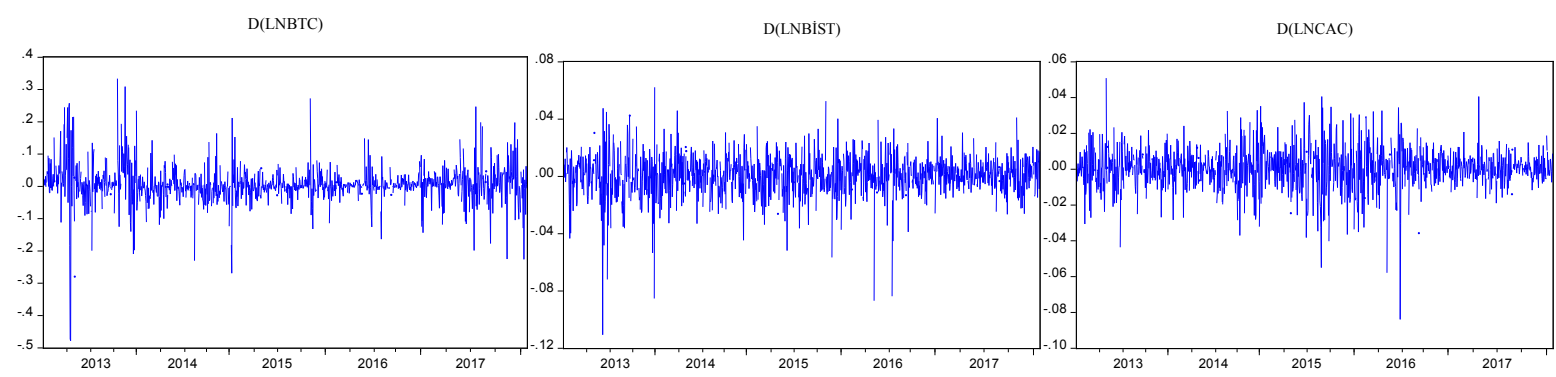

D(LNDAX)

D(LNFMIB)

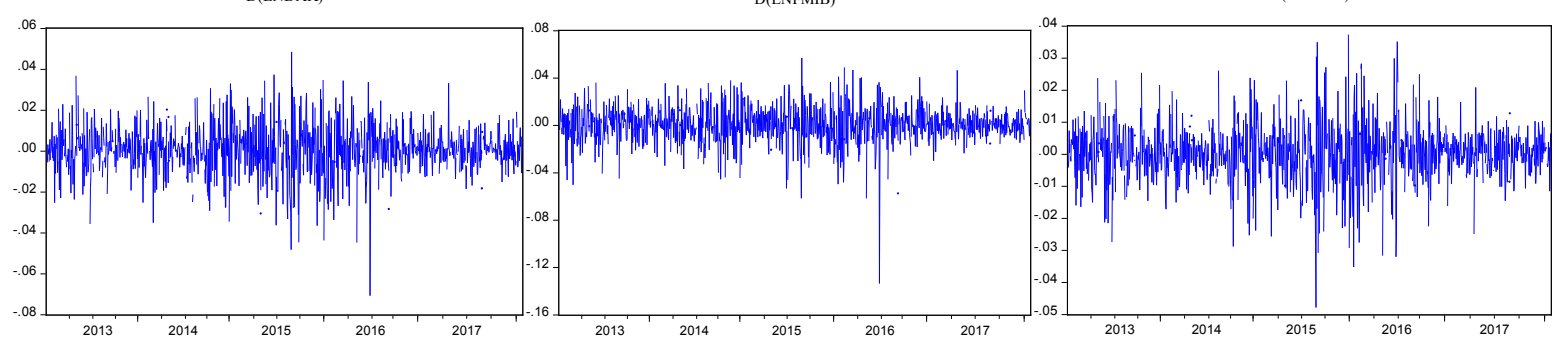



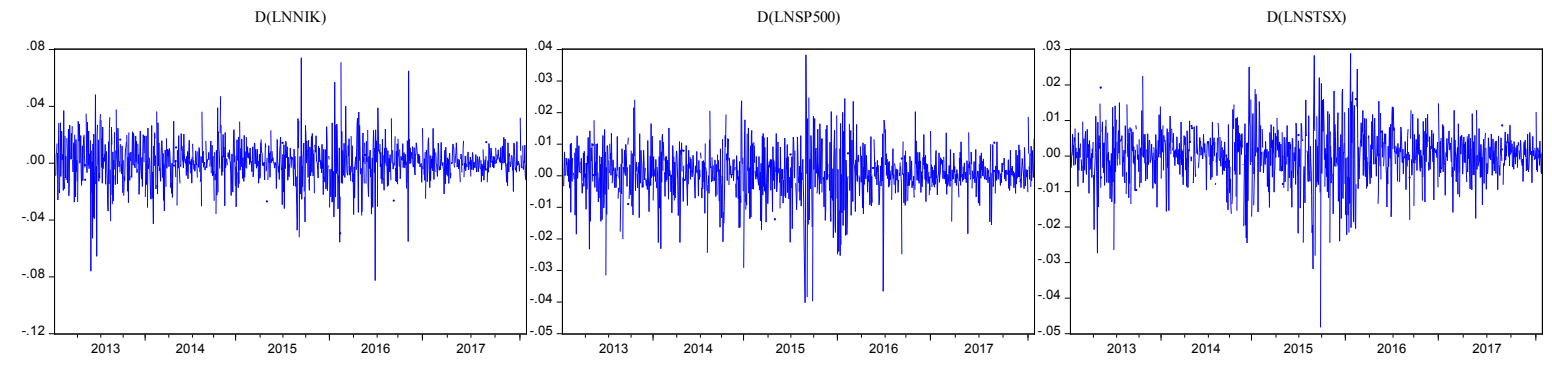

Birim kök testi sonuçlarına göre birinci farklarında durağan çıkan serilerimiz Johansen Eşbütünleşme testi için gerekli olan ön koşulu sağlamıştır ancak serilerin farkını almak serilerde veri kayıplarına neden olarak serilerin maruz kaldığ 1 şokları yok ettiği gibi uzun dönemli ilişkileri de yok etmektedir. Bu nedenle modelde kullanılan değişkenlere kısıtsız bir VAR modeli uygulanarak gecikme sayısının belirlenmesi gerekmektedir. Literatür incelendiğinde genellikle Akaike (AIC), Schwarz (SC) ve Hannan-Quinn (HQ) bilgi kriterlerinin temel aldığ gecikme uzunluklarının kullanıldığı görülmüştür. Uygun gecikme uzunluğu bu bilgi kriterler göz önünde bulundurularak iki (2) olarak seçilmiştir.

Johansen Eşbütünleşme testini yapmadan önce karar verilmesi gereken ikinci adım ise kullanılacak olan modeldir. Uygun model Johansen ve Jeselius (1992) tarafından önerilen Puntula prensibi kullanılarak Sabitli Trendsiz model olarak seçilmiştir.

Tablo 6: Johansen Eşbütünleşme Test Sonuçları

\begin{tabular}{|c|c|c|c|c|c|c|c|}
\hline \multicolumn{2}{|c|}{$\begin{array}{c}\text { Eşbütünleşik vektör } \\
\text { sayısı }\end{array}$} & \multicolumn{2}{|c|}{ İz (Trace) İstatistiği } & \multicolumn{2}{|c|}{$\begin{array}{c}\text { Eşbütünleşik vektör } \\
\text { sayısı }\end{array}$} & \multicolumn{2}{|c|}{$\begin{array}{c}\text { Maksimum Özdeğer } \\
\text { (Eigenvalue) İst. }\end{array}$} \\
\hline $\mathrm{H}_{0}$ & $\mathrm{H}_{1}$ & Test İstatistiği & Kritik Değer & $\mathrm{H}_{0}$ & $\mathrm{H}_{1}$ & $\begin{array}{c}\text { Test } \\
\text { İstatistiği }\end{array}$ & $\begin{array}{l}\text { Kritik } \\
\text { Değer }\end{array}$ \\
\hline $\mathrm{r}=0$ & $r \geq 1$ & $210.9391 *$ & 208.4374 & $\mathrm{r}=0$ & $r \geq 1$ & $65.87209 *$ & 59.24000 \\
\hline $\mathrm{r} \leq 1$ & $r \geq 2$ & 145.0670 & 169.5991 & $\mathrm{r} \leq 1$ & $r \geq 2$ & 52.88243 & 53.18784 \\
\hline $\mathrm{r} \leq 2$ & $r \geq 3$ & 92.18455 & 134.6780 & $\mathrm{r} \leq 2$ & $r \geq 3$ & 34.51383 & 47.07897 \\
\hline$r \leq 3$ & $r \geq 4$ & 57.67072 & 103.8473 & $r \leq 3$ & $r \geq 4$ & 17.97511 & 40.95680 \\
\hline$r \leq 4$ & $r \geq 5$ & 39.69561 & 76.97277 & $\mathrm{r} \leq 4$ & $r \geq 5$ & 13.96539 & 34.80587 \\
\hline$r \leq 5$ & $r \geq 6$ & 25.73022 & 54.07904 & $\mathrm{r} \leq 5$ & $r \geq 6$ & 11.17287 & 28.58808 \\
\hline$r \leq 6$ & $r \geq 7$ & 14.55734 & 35.19275 & $\mathrm{r} \leq 6$ & $\mathrm{r} \geq 7$ & 6.803548 & 22.29962 \\
\hline $\mathrm{r} \leq 7$ & $r \geq 8$ & 7.753795 & 20.26184 & $\mathrm{r} \leq 7$ & $r \geq 8$ & 5.447518 & 15.89210 \\
\hline $\mathrm{r} \leq 8$ & $\mathrm{r}=9$ & 2.306277 & 9.164546 & $\mathrm{r} \leq 8$ & $\mathrm{r}=9$ & 2.306277 & 9.164546 \\
\hline
\end{tabular}

Not: “*” \%5 seviyesinde anlamlılı̆̆ ifade etmektedir.

Belirlenen gecikme uzunluğu ile Johansen (1988) ve Johansen ve Jeselius (1990) eşbütünleşme testi sonuçları Tablo 5'te gösterilmiştir. İlk satırda gösterilen iz istatistiği ve maksimum öz değer istatistikleri \% 5 anlamlılık düzeyindeki kritik değerden yüksektir. Bu sonuçlar sıfır hipotezinin $\left(\mathrm{H}_{0}\right)$ reddedilmesini gerektirmektedir. Yani alternatif hipotez $\left(\mathrm{H}_{1}\right)$ kabul edilir ve seriler arasında en az bir adet eşbütünleşme vektörünün olduğu sonucu ortaya çıkar. Tablo 5 'te gösterilen bu sonuçlar, değişkenlerimize ait serilerin birbiriyle aralarında uzun dönemli ilişkinin olduğunu göstermektedir. Seriler arasında uzun dönemli ilişkilerin bulunduğu durumlarda VECM tahminin yapılması gerekmektedir. Hata terimi, 
eşbütünleşme regresyonundan elde edilen artıkları ifade etmektedir. Sonraki adımda değişkenlere ilişkin VECM tahmini yapılmış ve Tablo 6'da listelenmiştir.

Tablo 7: Bitcoin İle G7 Ülke Borsaları İçin VECM Sonuçları

\begin{tabular}{|c|c|c|c|c|c|c|c|c|c|}
\hline $\begin{array}{l}\text { Bağ̀nlı } \\
\text { Değiş. }\end{array}$ & $\triangle \mathrm{LNBTC}$ & $\triangle \mathrm{LNBİST}$ & $\triangle \mathrm{LNCAC}$ & $\triangle \mathrm{LNDAX}$ & 1LNFMIB & 1LNFTSE & $\triangle \mathrm{LNNIK}$ & $\triangle \mathrm{LNSP} 500$ & 1LNSTSX \\
\hline$E C_{-1}$ & $0.002645^{*}$ & $-1.73 \mathrm{E}-05$ & -0.00021 & $1.05 \mathrm{E}-05$ & 0.000139 & -0.00019 & $7.84 \mathrm{E}-05$ & 0.000157 & -0.00014 \\
\hline Standart & 0.00076 & 0.00019 & 0.00015 & 0.00015 & 0.00019 & 0.00011 & 0.00017 & 0.00010 & $9.4 \mathrm{E}-05$ \\
\hline Hata & 3.47212 & -0.09182 & -1.46161 & 0.07139 & 0.72575 & -1.78778 & 0.47294 & 1.56168 & -1.52731 \\
\hline t-istatistiğ $i$ & 0.0005 & 0.9269 & 0.1441 & 0.9431 & 0.4681 & 0.0741 & 0.6364 & 0.1187 & 0.1270 \\
\hline$R^{2}$ & 0.014111 & 0.021672 & 0.055866 & 0.046010 & 0.031385 & 0.100194 & 0.214059 & -0.004211 & 0.008840 \\
\hline
\end{tabular}

" $\Delta$ " değişkenlerin birinci dereceden farkını ifade etmektedir. “*” \%5 seviyesinde anlamlılı̆̆ ifade etmektedir.

Tablo 6'da gösterilen hata terimine $\left(E C_{-1}\right)$ ilişkin katsayıların negatif ve istatistiksel olarak anlamlı olması beklenmektedir. Bu durum VECM modelinin etkin bir şekilde çalıştığını ifade eder ve değişkenlerde meydana gelebilecek değişimlerin uzun dönemde yeniden dengeye geleceği şeklinde yorumlanır. Ancak Tablo 6 incelendiğinde yalnızca $\triangle$ LNBTC ait hata düzeltme teriminin istatistiksel olarak anlamlı olduğu görülmektedir. Ancak $\triangle$ LNBTC ait hata terimi anlamlı olmasına rağmen işareti pozitiftir (0.002645). Bu durum Bitcoin ile G7 ülkelerine ait borsaların uzun dönemli bir denge ilişkisi içerisinde olmadığını gösterirken Bitcoin'e ilişkin verilerin dengeden çıktıktan sonra giderek dengeden uzaklaştığı anlamına gelmektedir. Bitcoin ile G7 ülkelerine ait kısa dönemli nedensellik ilişkilerini incelemek için WALD testi yapılmış ve sonuçları Tablo 7'de gösterilmiştir. 
Tablo 8: WALD İstatistiği İle Granger Nedensellik Analizi

\begin{tabular}{|c|c|c|c|c|c|c|c|c|c|}
\hline & $\begin{array}{c}\text { LNBTC } \\
\chi^{2} \\
\text { (olasılik) }\end{array}$ & $\begin{array}{c}\text { LNBİST } \\
\chi^{2} \\
\text { (olasilik) }\end{array}$ & $\begin{array}{c}\text { LNCAC } \\
\chi^{2} \\
\text { (olasılik) }\end{array}$ & $\begin{array}{c}\text { LNDAX } \\
\chi^{2} \\
\text { (olasilik) }\end{array}$ & $\begin{array}{c}\text { LNFMIB } \\
\chi^{2} \\
\text { (olasılık) }\end{array}$ & $\begin{array}{c}\text { LNFTSE } \\
\chi^{2} \\
\text { (olasılık) }\end{array}$ & $\begin{array}{c}\text { LNNIK } \\
\chi^{2} \\
\text { (olasilik) }\end{array}$ & $\begin{array}{c}\text { LNSP500 } \\
\chi 2 \\
\text { (olas1l1k) }\end{array}$ & $\begin{array}{c}\text { LNSTSX } \\
\chi^{2} \\
\text { (olasilik) }\end{array}$ \\
\hline$L N B T C$ & & $\begin{array}{c}0.033877 \\
(0.9832)\end{array}$ & $\begin{array}{l}1.278138 \\
(0.5278)\end{array}$ & $\begin{array}{c}0.960922 \\
(0.6185)\end{array}$ & $\begin{array}{l}1.113509 \\
(0.5731)\end{array}$ & $\begin{array}{c}0.490292 \\
(0.7826)\end{array}$ & $\begin{array}{c}2.986981 \\
(0.2246)\end{array}$ & $\begin{array}{l}7.87494^{*} \\
(0.0195)\end{array}$ & $\begin{array}{l}6.10127 * \\
(0.0473)\end{array}$ \\
\hline LNBİST & $\begin{array}{c}0.137119 \\
(0.9337)\end{array}$ & & $\begin{array}{c}2.787496 \\
(0.2481)\end{array}$ & $\begin{array}{c}1.858565 \\
(0.3948)\end{array}$ & $\begin{array}{c}2.128638 \\
(0.3450)\end{array}$ & $\begin{array}{c}0.879209 \\
(0.6443)\end{array}$ & $\begin{array}{c}5.200633 \\
(0.0743)\end{array}$ & $\begin{array}{c}0.550451 \\
(0.7594)\end{array}$ & $\begin{array}{c}1.232300 \\
(0.5400)\end{array}$ \\
\hline$L N C A C$ & $\begin{array}{l}1.121684 \\
(0.5707)\end{array}$ & $\begin{array}{c}0.369734 \\
(0.8312)\end{array}$ & & $\begin{array}{c}1.948558 \\
(0.3775)\end{array}$ & $\begin{array}{c}4.778909 \\
(0.0917)\end{array}$ & $\begin{array}{c}3.215874 \\
(0.2003)\end{array}$ & $\begin{array}{c}0.364507 \\
(0.8334)\end{array}$ & $\begin{array}{c}2.075328 \\
(0.3543)\end{array}$ & $\begin{array}{c}1.375528 \\
(0.5027)\end{array}$ \\
\hline$L N D A X$ & $\begin{array}{c}0.903867 \\
(0.6364)\end{array}$ & $\begin{array}{l}1.298856 \\
(0.5223)\end{array}$ & $\begin{array}{c}1.697631 \\
(0.4279)\end{array}$ & & $\begin{array}{c}1.840332 \\
(0.3985)\end{array}$ & $\begin{array}{c}3.645100 \\
(0.1616)\end{array}$ & $\begin{array}{c}9.44526^{*} \\
(0.0089)\end{array}$ & $\begin{array}{l}1.476692 \\
(0.4779)\end{array}$ & $\begin{array}{c}0.750464 \\
(0.6871)\end{array}$ \\
\hline$L N F M I B$ & $\begin{array}{c}4.612740 \\
(0.0996)\end{array}$ & $\begin{array}{c}0.589123 \\
(0.7449)\end{array}$ & $\begin{array}{c}1.743132 \\
(0.4183)\end{array}$ & $\begin{array}{c}0.936263 \\
(0.6262)\end{array}$ & & $\begin{array}{c}0.604107 \\
(0.7393)\end{array}$ & $\begin{array}{c}0.604419 \\
(0.7392)\end{array}$ & $\begin{array}{l}1.409150 \\
(0.4943)\end{array}$ & $\begin{array}{c}0.097395 \\
(0.9525)\end{array}$ \\
\hline LNFTSE & $\begin{array}{c}6.07363^{*} \\
(0.0480)\end{array}$ & $\begin{array}{c}0.632817 \\
(0.7288)\end{array}$ & $\begin{array}{c}2.161525 \\
(0.3393)\end{array}$ & $\begin{array}{c}3.080038 \\
(0.2144)\end{array}$ & $\begin{array}{c}3.724235 \\
(0.1553)\end{array}$ & & $\begin{array}{c}3.663368 \\
(0.1601)\end{array}$ & $\begin{array}{c}0.211538 \\
(0.8996)\end{array}$ & $\begin{array}{c}0.022362 \\
(0.9889)\end{array}$ \\
\hline$L N N I K$ & $\begin{array}{c}0.091266 \\
(0.9554)\end{array}$ & $\begin{array}{c}3.538670 \\
(0.1704)\end{array}$ & $\begin{array}{c}0.727157 \\
(0.6952)\end{array}$ & $\begin{array}{c}2.928166 \\
(0.2313)\end{array}$ & $\begin{array}{c}0.480293 \\
(0.7865)\end{array}$ & $\begin{array}{c}3.221096 \\
(0.1998)\end{array}$ & & $\begin{array}{l}1.228621 \\
(0.5410)\end{array}$ & $\begin{array}{c}2.603827 \\
(0.2720)\end{array}$ \\
\hline LNSP500 & $\begin{array}{c}2.303700 \\
(0.3161)\end{array}$ & $\begin{array}{c}9.66332 * \\
(0.0080)\end{array}$ & $\begin{array}{c}37.8922 * \\
(0.0000)\end{array}$ & $\begin{array}{c}33.6928 * \\
(0.0000)\end{array}$ & $\begin{array}{c}23.3580 * \\
(0.0000)\end{array}$ & $\begin{array}{c}54.2273 * \\
(0.0000)\end{array}$ & $\begin{array}{c}55.4682 * \\
(0.0000)\end{array}$ & & $\begin{array}{c}0.017546 \\
(0.9913)\end{array}$ \\
\hline LNSTSX & $\begin{array}{c}4.263002 \\
(0.1187)\end{array}$ & $\begin{array}{c}1.258356 \\
(0.5330)\end{array}$ & $\begin{array}{c}3.431354 \\
(0.1798)\end{array}$ & $\begin{array}{l}1.214351 \\
(0.5449)\end{array}$ & $\begin{array}{c}1.224675 \\
(0.5421)\end{array}$ & $\begin{array}{c}7.41779 * \\
(0.0245)\end{array}$ & $\begin{array}{c}4.301791 \\
(0.1164)\end{array}$ & $\begin{array}{c}0.511270 \\
(0.7744)\end{array}$ & \\
\hline$T \ddot{U} M \ddot{U}$ & $\begin{array}{c}19.80259 \\
(0.2292)\end{array}$ & $\begin{array}{c}39.3380^{*} \\
(0.0010)\end{array}$ & $\begin{array}{c}78.1347^{*} \\
(0.0000)\end{array}$ & $\begin{array}{c}68.8028^{*} \\
(0.0000)\end{array}$ & $\begin{array}{c}47.7754^{*} \\
(0.0001)\end{array}$ & $\begin{array}{c}131.623^{*} \\
(0.0000)\end{array}$ & $\begin{array}{c}312.123^{*} \\
(0.0000)\end{array}$ & $\begin{array}{c}15.68183 \\
(0.4754)\end{array}$ & $\begin{array}{c}21.14465 \\
(0.1730)\end{array}$ \\
\hline
\end{tabular}

Tablodaki ilk değerler ki-kare $(\chi 2)$ istatistik değerleridir. Parantez içerisindeki değerler p- olasılık değerleridir.

Tablo 7'de Granger nedensellik/Wald testi ile ilgili olarak gösterilen sonuçlar her bir denkleme ilişkin bağımsız değişkenlerin gecikmeli değerlerinin, bağımlı değişkenin nedeni olup olmadığını göstermektedir. Tablo 7'deki sonuçlar bağımsız değişkenlerdeki gecikmeli değerlerin çoğunun denklemden dışlanabileceğine yönelik ampirik kanıtlar sunmaktadır. Çünkü bağımsız değişkenlerdeki gecikmeler genel olarak istatistiki olarak anlamsız bulunmuştur. Temel araştırma denklemimiz için Bitcoin'in bağımlı değişken olarak gösterildiği modelin sonuçları baz alındığında; sadece FTSE'deki gecikmelerin Bitcoin'in nedeni olduğu görülmektedir. Nedensellik analizine ilişkin sonuçlar Şekil 2 yardımıyla özetlenmiştir. 


\section{Şekil 2: Bitcoin İle Türkiye Ve G7 Ülke Borsaları Arasındaki Nedensellik İlişkisi}

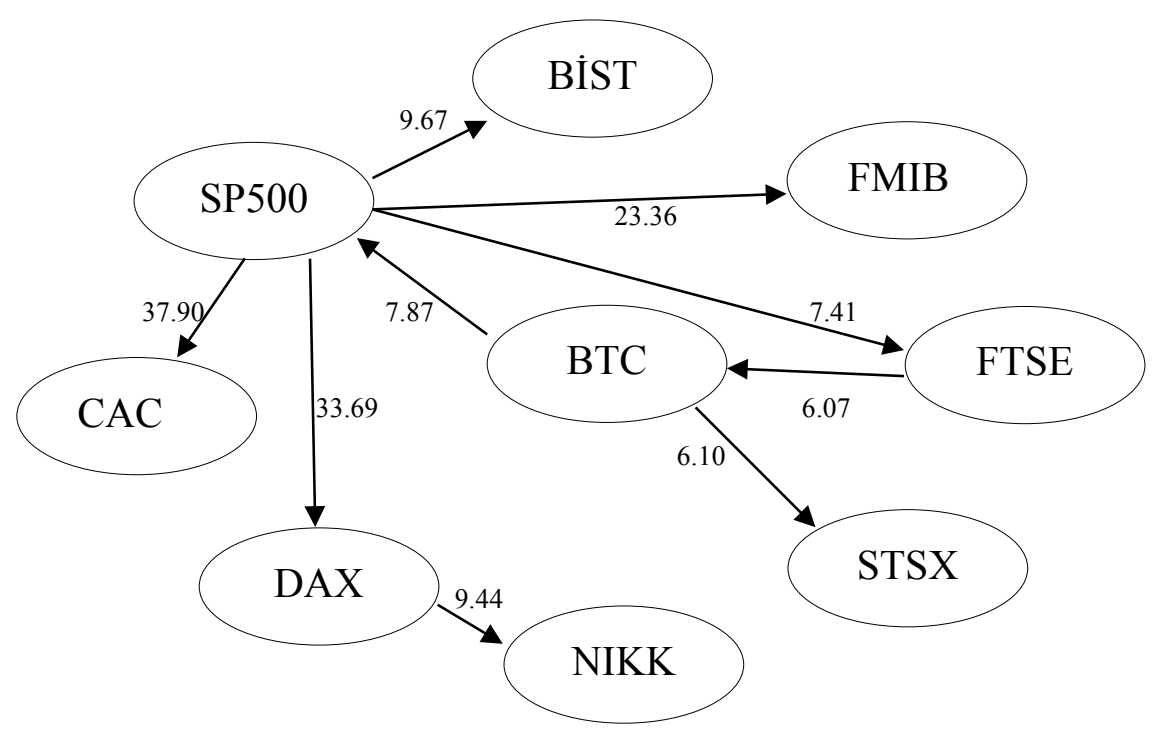

Şekil 2 incelendiğinde en çarpıcı sonucun FTSE'deki gecikmelerin Bitcoin'in nedeni olduğu görülmektedir. Diğer yandan Bitcoin'deki gecikmelerin ise SP500 ve STSX'in nedeni olduğu görülmektedir. Bitcoin ile FTSE, SP500 ve STSX dışında kalan ülke borsaları arasında herhangi bir nedensellik ilişkisi saptanmamıştır. Sonuçlar bir bütün olarak değerlendirildiğinde SP500'ün çalışmaya konu olan çoğu borsa endeksinin nedeni olduğu anlaşılmaktadır.

\section{SONUÇLAR}

Bugüne kadar yapılan benzer çalışmaların büyük çoğunluğunda, Bitcoin ile borsa endeksleri arasında kısa dönemli ilişkiden daha çok uzun dönemli ilişskiler ortaya koyulmuştur ve yapılan literatür çalışmasına göre bu ilişsilerin ABD ve Çin borsa endeksleri ile olduğu anlaşılmaktadır. Ayrıca, literatür araştırmasında döviz kurları ile Bitcoin arasındaki Granger nedensellik ilişkisine bakıldığında, Japon Yeni’nden Bitcoine doğru bir nedensellik ilişkisi tespit edilmiştir.

Bu çalışmada ise Bitcoin ile Türkiye ve G7 ülke borsaları arasındaki uzun ve kısa dönemli ilişkiler araştırılmıştır. Son günlerde oldukça popüler olan ve yatırım aracı olarak görülüp görülemeyeceği tartışma yaratan Bitcoin'in, borsalarla birlikte hareket edip etmediği araştırılarak yatırımcıların portföy çeşitlendirmesi yoluyla risklerini azaltıp azaltamayacakları tespit edilmeye çalışılmıştır. Analiz sonuçlarına göre Bitcoin ile borsalar arasında uzun dönemli ilişkileri gösteren Eşbütünleşme analizi sonuçlarına göre bir ilişkinin varlığı tespit edilse de bu ilişkinin denge içerisinde olmadığ1 ve uzun dönem için Bitcoin fiyatlarının borsalardan bağımsız bir şekilde hareket ettiği görülmüştür. Yani yatırımcılar hem araştırmaya konu olan bu borsalar arasında hem de Bitcoin'e yatırım yaparak risklerini çeşitlendirme yoluna gidebilirler.

Kısa dönemli ilişkileri inceleyen Granger Nedensellik/Wald testi sonuçlarına göre İngiltere borsasının Bitcoin'in nedeni olduğu bulunurken, Bitcoin'in ise Amerika ve Kanada borsalarının nedeni olduğu görülmüştür. Kısaca, yatırımcılar bu üç borsa endeksine bakarak Bitcoin'in fiyatlarındaki kısa dönemli dalgalanmalar hakkında fikir sahibi olabilirler.

Bitcoin ile ilgili olarak gelecekteki çalışmalar için iki yaklaşım önerilmektedir. Birincisi; Bitcoin fiyatlarındaki dalgalanmaların kalıcı olup olmadığı veya zaman içerisinde bozulup bozulmadığını görebilmek için bu çalışma farklı zaman dilimleri için tekrarlanabilir. İkincisi; başka ülke borsaları da çalışmaya dahil edilerek araştırmanın kapsamı genişletilebilir ve Bitcoin'i yaygın olarak yatırım aracı olarak kullanan ülkelerin döviz kurları ile Bitcion arasındaki nedensellik ilişkileri araştırılabilir. 


\section{Kaynakça}

Altıntaş, H. ve Mercan, M. (2015), “Ar-Ge Harcamaları Ve Ekonomik Büyüme İlişkisi: Oecd Ülkeleri Üzerine Yatay Kesit Bağımlılığı Altında Panel Eşbütünleşme Analizi” Ankara Üniversitesi SBF Dergisi, 70(2), 345-376.

Atik, M., Köse, Y., Yılmaz, B., \& Sağlam, F. (2015). Kripto Para: Bitcoin ve Döviz Kurları Üzerine Etkileri. Bartın Üniversitesi İ̈BF Dergisi, 6(11); ss: 247-261.

Bayraktutan, Y. ve Arslan, İ. (2008), “Türkiye'de Sabit Sermaye Yatırımlarının Ekonomik Büyüme Üzerindeki Etkisi: Ko Entegrasyon Analizi (1980-2006)” KMU IIIBF Dergisi, 14, 1-12.

Chen, B. ve Chen A. (2009), "Empirical Test of the Relationship Between Technology Transfer and Independent R\&D”, International Conference Information Management, Innovation Management and Industrial Engineering. 26-27 Aralık, Xi'an, Chine.

Çağlayan, E., ve Saçaklı, N. (2006). "Satın Alma Gücü Paritesinin Geçerliliğinin Sıfır Frekansta Spektrum Tahmincisine Dayanan Birim Kök Testleri ile İncelenmesi”, Atatürk Üniversitesi İIBF Dergisi, 20, 121-137.

Demirci, N. Savaş (2017). “İmalat Sanayi Sektöründe Üretim ve Banka Kredileri İlişkisi: Türkiye için Eşbütünleşme ve Nedensellik Analizi”, Dokuz Eylül Üniversitesi Sosyal Bilimler Enstitüsü Dergisi, 19(1); ss: 35-61.

Dirican, C., \& Canöz, İ. (2017). "Bitcoin Fiyatları ile Dünyadaki Başlıca Borsa Endeksleri Arasındaki Eşbütünleşme İlişkisi: Ardl Modeli Yaklaşımı ile Analiz. Journal of Economics Finance and Accounting, 4(4); ss: 377-392.

Eryiğit, M. ve Öget E. (2015), "Causality Relationships Between BIST100 and Some Developed Stock Market Indices", Multidisciplinary Academic Conference on Economics, Management and Marketing. 6-7 Ağustos, Prag, Çek Cumhuriyeti.

Enders, W. (2004), “Applied Econometric Time Series”, John Wiley ve Sons, New York.

Gandal, N., Hamrick, J., Moore, T., \& Oberman, T. (2018). Price Manipulation in the Bitcoin Ecosystem. Journal of Monetary Economics, 1; ss: 1-11.

Glaser, F., Zimmermann, K., Haferkorn, M., Weber, M. C., \& Siering, M. (2014). Bitcoin - Asset or Currency? Revealing Users' Hidden Intentions. ECIS2014 (Twenty Second European Conference on Information Systems), (s. 1-14). Tel Aviv.

Gupta, K., Agrawal, S., \& Bharadwaj, A. (2015). Dependability of Bitcoin in E-Commerce. BICON (10th Biyani International Conference) (s. 74-76). Jaipur: Biyani Institute of Commerce \& Management Pvt. Ltd.

Gültekin, Y., \& Bulut, Y. (2016). Bitcoin Ekonomisi: Bitcoin Eko-Sisteminden Doğan Yeni Sektörler ve Analizi. Adnan Menderes Üniversitesi Sosyal Bilimler Enstitüsü Dergisi, 3(3); ss: 82-92.

Işık, N., Acar, M. ve Işık. B. (2004), "Enflasyon ve Döviz Kuru İlişkisi: Bir Eşbütünleşme Analizi”, Süleyman Demirel Üniv, İ̈BF Dergisi, 9(2), 325-340.

Kilian L. ve Lütkepohl H. (2017), "Structural Vector Autoregressive Analysis", Cambridge Universty Press. Cambridge, İngiltere.

Koçoğlu, Ş., Çevik, Y. E., \& Tanrı̈ven, C. (2016). Bitcoin Piyasalarının Etkinliği, Likiditesi ve Oynaklığı. İşletme Araştırmaları Dergisi, 8(2); ss: 77-97.

Kolçak, M., Kalabak, A. Y. ve Boran, H. (2017), “Kamu Harcamaları Büyüme Üzerinde Bir Politika Aracı Olarak Kullanılmalı Mı? VECM Analizi ve Yapısal Kırılma Testleri İle Ampirik Bir Analiz: 1984-2014 Türkiye Örneği” Ankara Üniversitesi SBF Dergisi, 72(2), 467 - 486.

Nakamoto, S. (2008). Bitcoin: A Peer-to-Peer Electronic Cash System. http://www.bitcoin.org/bitcoin.pdf, Erişim Tarihi: 23.11.2017. 
Özcan, M. (2015), "Nonlinear Dynamics In Financial Time Series And Unit Root Tests: Case Of Borsa Istanbul Sectoral Price-Earning Ratios” Journal of Economics, Finance and Accounting, 2(4), ISSN: 2148-6697

Pınarönü, N. (2007), “Johansen ve Kısmi Lineer Tekil Değer Eşbütünleşme Testlerinin Bir Uygulama Problemi Üzerinde Karşılaştırılması”, Yayınlanmamış Yüksek Lisans Tezi. Gazi Üniversitesi Fen Bilimleri Enstitüsü, Ankara.

Sönmez, A. (2014). Sanal Para Bitcoin. The Turkish Online Journal of Design, Art and Communication, 4(3); ss: 114.

Tarı, R. ve Yıldırım D. Ç. (2009), “Döviz Kuru Belirsizliğinin İhracata Etkisi: Türkiye İçin Bir Uygulama”, Yönetim ve Ekonomi, 16(2), 95-105.

Uğurlu, E. (2009), “Durağanlık Ve Birim Kök Sınamaları” İstanbul Aydın Üniversitesi Ekonomi ve Finans Bölümü (Ders Notlari), 1-17. 